\title{
Serum amyloid A levels and alpha 2 and gamma globulins on serum protein electrophoresis in cats exposed to and infected with Leishmania infantum
}

\author{
Giulia Savioli ${ }^{*}$, Joy Archer ${ }^{1}$, Emanuele Brianti ${ }^{2}$, Giovanni Benelli ${ }^{3}$, Manuela Schnyder ${ }^{4}$, Roberta latta ${ }^{5}$, \\ Domenico Otranto ${ }^{5}$ and Cinzia Cantacessi $1^{*}$ (D)
}

\begin{abstract}
Background: Dogs are the main reservoir hosts of Leishmania infantum; nevertheless, recent investigations indicate a likely role for cats in the epidemiology of Leishmania infection. Feline leishmaniosis (FeL) remains poorly characterised, partly due to the lack of suitable diagnostic tools. This study aimed to compare serum amyloid A (SAA) levels and serum protein electrophoresis (SPE) profiles (specifically, alpha 2 and gamma globulins) in cats naturally exposed to or infected by L. infantum from southern Italy versus those of healthy controls and versus cats with neoplastic or inflammatory conditions from non-endemic areas.

Methods: Serum or plasma samples from four cohorts of cats were analysed for SAA levels and by SPE: (i) G1: healthy controls from Leishmania-non-endemic regions of Switzerland; (ii) G2: cats pre-diagnosed with neoplastic or inflammatory conditions available from the University of Cambridge sample archive; (iii) G3: L. infantum-seropositive, quantitative (q)PCR-negative cats from southern Italy; (iv) G4: L. infantum-seropositive and qPCR-positive cats from southern Italy. SAA data were assessed for normality and homoscedasticity using the Shapiro-Wilk and Levene's tests, respectively; the Kruskall-Wallis test, followed by Dunn's test with Bonferroni correction were subsequently used to compare SAA serum levels between groups. A weighted generalised linear model with a binomial distribution was used to assess statistically significant differences in the numbers of animals displaying elevated gamma globulins and increased alpha 2 globulins between groups.
\end{abstract}

Results: Overall, 68 samples were analysed (G1: $n=16, \mathrm{G} 2: n=20, \mathrm{G} 3: n=20, \mathrm{G} 4: n=12)$. Cats suffering from neoplastic and inflammatory conditions (G2) showed significantly higher SAA levels than healthy controls (G1) (median values [interquartile range]: G1:0.00 [0.00-0.00] mg/l versus G2:0.85 [0.00-49.55] mg/l). G2, G3 and G4 cats showed higher percentages of individuals with increased alpha 2 globulins (percentages \pm standard error: $G 1=20.0 \% \pm 10.3$, $\mathrm{G} 2=80.0 \% \pm 8.9, \mathrm{G} 3=70.0 \% \pm 10.2, \mathrm{G} 4=75.0 \% \pm 12.5)$ and gamma globulins $(\mathrm{G} 1=0.0 \% \pm 0, \mathrm{G} 2=65.0 \% \pm 10.7$, $\mathrm{G} 3=50.0 \% \pm 11.2, \mathrm{G} 4=58.3 \% \pm 14.2$ ) than healthy control cats (G1). For all three markers, no significant difference between cats within $\mathrm{G} 2, \mathrm{G} 3$ and $\mathrm{G} 4$ was recorded.

\footnotetext{
*Correspondence: giuliasavioli@hotmail.com; cc779@cam.ac.uk

1 Department of Veterinary Medicine, University of Cambridge, Cambridge, UK

Full list of author information is available at the end of the article
}

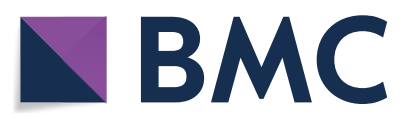

(c) The Author(s) 2021. This article is licensed under a Creative Commons Attribution 4.0 International License, which permits use, sharing, adaptation, distribution and reproduction in any medium or format, as long as you give appropriate credit to the original author(s) and the source, provide a link to the Creative Commons licence, and indicate if changes were made. The images or other third party material in this article are included in the article's Creative Commons licence, unless indicated otherwise in a credit line to the material. If material is not included in the article's Creative Commons licence and your intended use is not permitted by statutory regulation or exceeds the permitted use, you will need to obtain permission directly from the copyright holder. To view a copy of this licence, visit http://creativeco mmons.org/licenses/by/4.0/. The Creative Commons Public Domain Dedication waiver (http://creativecommons.org/publicdomain/ zero/1.0/) applies to the data made available in this article, unless otherwise stated in a credit line to the data. 
Conclusions: This study indicates that the proportions of animals with elevated levels of alpha 2 and gamma globulins are significantly higher in cats exposed to and infected with L. infantum. Levels of SAA and alpha 2 and gamma globulins may not be used to differentiate between L. infantum infection or exposure, and neoplastic and/or inflammatory conditions.

Keywords: Acute phase protein, Alpha 2 globulins, Feline leishmaniosis, Gamma globulins, Leishmania infantum, Phlebotomine sand flies, Serum amyloid A, Serum protein electrophoresis

\section{Background}

Zoonotic visceral leishmaniosis (ZVL) is a neglected disease caused by Leishmania infantum, transmitted by Phlebotomus spp. sand flies in the Old World [1]. The disease is distributed worldwide and endemic in many regions, including the Mediterranean basin [2]. Dogs are the main reservoir hosts of L. infantum [3]. Canine leishmaniosis (CanL) is endemic in Italy, and the prevalence of infection has increased with its spread from hyperendemic southern and central areas towards northern regions [4]. The epidemiological role of other animal species as alternative reservoir hosts of L. infantum has long been overlooked. Nevertheless, recent epidemiological investigations in other species have pointed towards the likely implication of domestic and wild felids in parasite circulation [5-8]. In particular, endemic foci of feline leishmaniosis (FeL) have recently been described in southern Italy, and the overall prevalence of feline infection in these areas is likely underestimated $[9,10]$.

FeL is often subclinical [11-13], with clinical cases mainly characterised by cutaneous lesions, with crusty or nodular dermatitis being the most common presentation [14], whilst lymphadenomegaly seldom reported [5]. Typical diagnostic samples include skin (lesions), lymph node, bone marrow and blood [14, 15]. When present, clinical signs are non-specific, and alterations in haematological, biochemical and urinary profiles, typically detected in dogs with leishmaniosis [16], may support suspicion of FeL. Due to the frequently subclinical nature of the infection, a straightforward measure of disease progression and response to treatment would facilitate the clinical management of FeL. The measurement of acute phase proteins (APPs), including C-reactive protein (CRP), haptoglobin and serum amyloid A (SAA), is increasingly being applied to the diagnosis, monitoring and prognosis of a range of veterinary inflammatory conditions $[17,18]$, including $L$. infantum infection in dogs $[16,19]$.

The acute phase response is an early, non-specific defence mechanism characterised by the release of proinflammatory cytokines that stimulate an increase in serum APPs in response to infection, inflammation, tissue injury, neoplasia and other processes [20]. In dogs naturally infected by $L$. infantum, a significant increase in the release of APPs, including CRP, haptoglobin and ceruloplasmin is observed, irrespective of the occurrence of clinical signs [19]. SAA is considered to be a less sensitive indicator of CanL compared to other APPs [21]; nevertheless, SAA is a major indicator of feline inflammatory conditions, including trauma, post-operative inflammation and sepsis [22-24]. SAA is substantially increased in cats with clinical signs of vector-borne infections, such as those caused by Hepatozoon felis and Babesia vogeli, compared to uninfected and subclinically infected cats [25]. Recently, protein-related laboratory abnormalities were reported in tigers naturally infected by $L$. infantum [26]. While information on serum APP levels in cats infected with vector-borne pathogens remains limited [25], these findings may suggest a useful diagnostic and prognostic role for SAA.

Serum protein electrophoresis (SPE) is a straightforward method to measure specific serum proteins and separate these into fractions. The alpha 2 fraction in SPE contains a number of APPs; thus its quantification may be useful to diagnose inflammatory processes [27]. However, the levels of alpha 2 globulin in SPE in FeL have, thus far, not been investigated in detail. In one study, FeL-infected cats showed significantly lower levels of the alpha 2 globulin fraction compared to uninfected cats, with median alpha 2 globulin levels remaining within the reference range for infected cats [28]. In another study, FeL-positive cats did not show significantly higher alpha 2 globulin levels compared to negative controls [29]. SPE is commonly used to identify and characterise gammopathy in dogs infected by L. infantum [16, 30]. Gammopathy normally occurs in both CanL and FeL $[15,28,29]$.

In this scenario, the aim of the present study was to evaluate and compare the serum SAA levels and SPE profiles, specifically those of alpha 2 and gamma globulins, in cats from a ZVL-endemic area naturally exposed to or infected by L. infantum versus healthy cats and cats with pre-diagnosed neoplastic or inflammatory conditions.

\section{Methods \\ Enrolment and diagnostic procedures}

A total of 68 serum or plasma samples were obtained from four groups of cats: 
Group 1 (G1): 16 healthy control cats from Leishmania-non-endemic regions of Switzerland (north of the Alps). The samples originated from the archives of the Clinical Laboratory or the Institute of Parasitology, Vetsuisse Faculty, University of Zurich (VetLab Zurich and IPZ, respectively), and included healthy stray cats recruited into a spay/neuter programme $(n=5)$, healthy blood donors $(n=6)$ and healthy laboratory cats $(n=5)$. All cats were recorded as clinically healthy following a thorough clinical examination by an accredited veterinary surgeon. Routine haematology and biochemistry analyses were performed with samples from blood donors, and animals that had travelled abroad were excluded. Cats from the spay and neuter programme were recruited only from the north of the Alps, a Leishmania-free area. Laboratory animals are born and kept in controlled experimental units, with no exposure to Phlebotominae. The G1 group included 3 plasma and 13 serum samples.

Group 2 (G2): 20 cats pre-diagnosed with neoplastic or inflammatory conditions selected from the sample archive of the Queen's Veterinary School Hospital of the University of Cambridge. These cats originated from a Leishmania-free, namely the UK, and had not travelled abroad.

Group 3 (G3): 20 cats from southern Italy (i.e. Aeolian Islands, Sicily and Apulia regions) testing seropositive for $L$. infantum by immune-fluorescence antibody test (IFAT), but negative by quantitative (real-time) PCR (qPCR).

Group 4 (G4): 12 cats from southern Italy (Aeolian Islands, Sicily) testing seropositive by IFAT and qPCR positive for L. infantum.

G3 and G4 samples were derived from previous published studies on FeL conducted in southern Italy [10]. In particular, all cats included in the study by Otranto et al. [10] were tested for co-infections with other vector-borne diseases (VBDs) (i.e. Anaplasma spp., Babesia spp., Ehrlichia spp., Hepatozoon spp. and Bartonella spp.) as well as with feline leukaemia and feline immunodeficiency viruses (FeLV and FIV, respectively). Only samples from cats that tested positive for Leishmania, but negative for other VBDs and FIV and FeLV infections, were assessed in the present study.

Detection of antibodies against $L$. infantum was performed by IFAT, as described by Otranto et al. [31], using a cut-off value of 1:80 [32]. Blood and conjunctival swabs from the enrolled cats were subjected to DNA extraction, using the DNeasy Blood \& Tissue Extraction Kit (Qiagen, Hilden, Germany), according to the manufacturer's instructions. The detection of a L. infantum kinetoplast
DNA minicircle fragment (120 bp) was achieved by qPCR, using primers, probes and protocol described elsewhere [33].

\section{SAA and serum protein electrophoresis}

The SAA concentrations were determined using a turbidimetric immunoassay kit (LZ-SAA; Eiken Chemical Co., Tokyo, Japan), with analysis on an automated analyser (Olympus AU480; Beckman Coulter Inc., Fullerton, USA). SPE was performed on alkaline buffered agarose gels using the Hydragel Protein(e) K20 electrophoresis system (SEBIA, Lisses, France), according to the manufacturer's instructions, using $10-\mu \mathrm{l}$ of each serum sample. The gels were analysed with the Perfection V700 Photo imaging densitometer (Seiko Epson Corp., Suwa, Nagano, Japan), using SEBIA Phoresis Rel 8.6.3 software (Magiras Diagnostics, Likovrisi, Greece). Total protein was measured using the biuret method on an automated analyser (Olympus AU480; Beckman Coulter Inc.). The numbers of cats whose plasma/sera displayed increased alpha 2 and gamma peaks on SPE were counted for each group according to reference intervals calculated by Taylor and colleagues [27]. Clonality of increased gamma peaks was assessed, with monoclonal gammopathies (as opposed to polyclonal gammopathies) defined as showing a narrow gamma peak, with a base width similar to the albumin peak or with peak height exceeding four-fold the peak width [27].

\section{Statistical analyses}

The values of SAA within each group were neither normally distributed (Shapiro-Wilk test, $W=0.47, P<0.001$ ) nor homoscedastic (Levene's test, $F_{3,63}=11.30, P<0.001$ ). Data transformation did not allow distribution normalisation nor variance homogenisation. Therefore, non-parametric statistical tests were used. The Kruskall-Wallis test, followed by Dunn's multiple comparison test with Bonferroni correction, was used to compare SAA serum levels between groups. Standard errors for the proportions (SEp) were calculated as: $\mathrm{SEp}=\sqrt{p(1-p) / n}$.

Differences in the numbers of cats displaying increased alpha 2 globulins and gamma globulins between groups were analysed by using a weighted generalised linear model (GLZ) with a binomial distribution to model increased alpha 2 globulins and gamma globulins outcomes. For both parameters, a GLZ with a fixed factor was used: $y=X \beta+\varepsilon$, where $y$ is the vector of the observation (i.e. outcome: increased $=1$, not increased $=0$ ), $X$ is the incidence matrix, $\beta$ is the vector of the fixed effect (i.e. the tested group) and $\varepsilon$ is the vector of the random residual effects $(P=0.05)$. 
All statistical analyses were performed with $\mathrm{JMP}^{\circledR} 9$ (SAS Institute, Cary, NC, USA) with $\alpha=0.05$ as threshold to detect significant differences.

\section{Results}

Of 68 samples analysed, one G1 (healthy control) sample did not undergo SPE, while one G4 (positive for L. infantum by both IFAT and qPCR) sample did not undergo SAA analysis as insufficient sample was available (Table 1).

Median values and interquartile ranges of SAA concentration in pathological groups were as follows: $\mathrm{G} 2=0.85(0.0-49.55) \mathrm{mg} / \mathrm{l}, \mathrm{G} 3=0.0(0.0-4.53) \mathrm{mg} / \mathrm{l}$ and $\mathrm{G} 4=0.0(0.0-7.5) \mathrm{mg} / \mathrm{l})$; in $\mathrm{G} 1$, values of $0.00(0.0-0.00)$ $\mathrm{mg} / \mathrm{l}$ were recorded. SAA concentrations differed significantly among tested groups $\left(\chi^{2}=13.56, d f=3, P=0.004\right)$. In particular, this marker was significantly higher in G2 when compared to G1 controls $(Z=3.62, d f=1$, $P=0.002$ ), while no significant differences were detected between G3 or G4 versus G1. No differences in SAA concentration were detected among G2, G3 and G4 (Fig. 1).

The proportion of cats showing increased alpha 2 and gamma globulins on SPE differed significantly among experimental groups $\left(\chi^{2}=15.56, d f=3, P=0.0014\right.$ and $X^{2}=22.225, d f=3, P<0.0001$, respectively) (Fig. 1). In particular, the proportion of cats showing increased alpha 2 globulins on SPE was significantly higher in cats from G2, G3 and G4 (percentage \pm SE: G2 $=80.0 \% \pm 8.9$, $\mathrm{G} 3=70.0 \% \pm 10.2, \quad \mathrm{G} 4=75.0 \% \pm 12.5) \quad$ compared to healthy controls $(\mathrm{G} 1=20.0 \% \pm 10.3$ and $0 \% \pm 0)(\mathrm{G} 1$ versus $\mathrm{G} 2: \chi^{2}=13.23, d f=1, P=0.0003$; $\mathrm{G} 1$ versus $\mathrm{G} 3$ : $x^{2}=9.05, d f=1, P=0.003 ; \mathrm{G} 1$ versus $\mathrm{G} 4: X^{2}=8.59$, $d f=1, P=0.003)$. A comparable trend was observed in the proportion of cats showing increased gamma globulins on SPE, which was significantly higher in cats from G2, G3 and G4 $(\mathrm{G} 2=65.0 \% \pm 10.7, \mathrm{G} 3=50.0 \% \pm 11.2$, $\mathrm{G} 4=58.3 \% \pm 14.2$ ) compared to healthy controls
$(\mathrm{G} 1=0 \% \pm 0)\left(\mathrm{G} 1\right.$ versus $\mathrm{G} 2: \chi^{2}=20.28, d f=1, P<0.0001$; G1 versus $\mathrm{G} 3: \chi^{2}=14.15, d f=1, P=0.0002$; $\mathrm{G} 1$ versus $\mathrm{G} 4$ : $\left.\chi^{2}=14.60, d f=1, P=0.0001\right)$. No significant difference in the proportion of animals displaying increased alpha 2 globulins or increased gamma globulins between G2, G3 and G4 was observed (Fig. 1). In all cases, gammopathy was polyclonal (not shown).

\section{Discussion}

In this study, SAA concentration was significantly higher in cats with neoplastic or inflammatory conditions (G2) than in healthy controls (G1), whereas no significant differences in SAA concentrations were noted between Leishmania-infected (G3) or -exposed (G4) cats compared to healthy animals. Previous studies had shown that elevated SAA levels are associated with clinically overt cases of feline $H$. felis and B. vogeli infection [25]. In contrast, our data suggests that SAA concentration is not reliably linked to FeL.

The percentages of animals showing elevated alpha 2 globulins were significantly higher in infected and exposed cats (G3 and G4) compared to healthy controls (G1), suggesting that the elevation of these markers, indicating an acute phase response, is a significant feature of FeL. However, elevated alpha 2 globulins were also observed in cats with neoplastic and inflammatory conditions compared with healthy controls, and therefore may not be considered robust indicators of FeL. Nevertheless, increased alpha 2 globulins are a recognised feature of infection in dogs [16], whereas previous studies on FeL have revealed either no significant difference in alpha 2 globulin levels between infected and uninfected cats [29], or significantly lower alpha 2 globulins in FeL-infected cats [28]. In both above-mentioned studies [28, 29], the median alpha 2 globulin levels for infected cats remained within the reference range. However, the methodology implemented in our study differed in that we compared

Table 1 Number of sampled cats, and serum protein electrophoresis and serum amyloid A results

\begin{tabular}{|c|c|c|c|c|}
\hline Variable & $\begin{array}{l}\text { GROUP } 1 \\
\text { Healthy control }\end{array}$ & $\begin{array}{l}\text { GROUP } 2 \\
\text { Neoplastic or } \\
\text { inflammatory conditions }\end{array}$ & $\begin{array}{l}\text { GROUP } 3 \\
\text { Leishmania infantum } \\
\text { seropositive, qPCR-negative }\end{array}$ & $\begin{array}{l}\text { GROUP } 4 \\
\text { L. infantum } \\
\text { seropositive, qPCR } \\
\text { positive }\end{array}$ \\
\hline Total number of samples analysed & 16 (15 for SPE) & 20 & 20 & $12(11$ for SAA) \\
\hline SAA results $(\mathrm{mg} / \mathrm{l})^{\mathrm{a}}$ & $0.00(0.00-0.00)$ & $0.85(0.00-49.55)$ & $0.00(0.00-4.53)$ & $0.00(0.00-7.5)$ \\
\hline \multicolumn{5}{|l|}{ SPE results ${ }^{b}$} \\
\hline Alpha 2 globulins increased & $3(20.0 \pm 10.3)$ & $16(80.0 \pm 8.9)$ & $14(70.0 \pm 10.2)$ & $9(75.0 \pm 12.5)$ \\
\hline Gamma globulins increased & $0(0 \pm 0)$ & $13(65.0 \pm 10.7)$ & $10(50.0 \pm 11.2)$ & $7(58.3 \pm 14.2)$ \\
\hline
\end{tabular}

qPCR Quantitative (real-time) PCR, SAA serum amyloid A, SPE serum protein electrophoresis

Reference ranges: SAA (mg/l): <0.5; alpha 2 globulins (g/l) [27]: 2.94-10.25; gamma globulins (g/l) [27]): 4.33-21.40

a Data presented as median (interquartile range)

${ }^{b}$ Data presented as a number (percentage \pm standard error on the percentage [SEP]) 

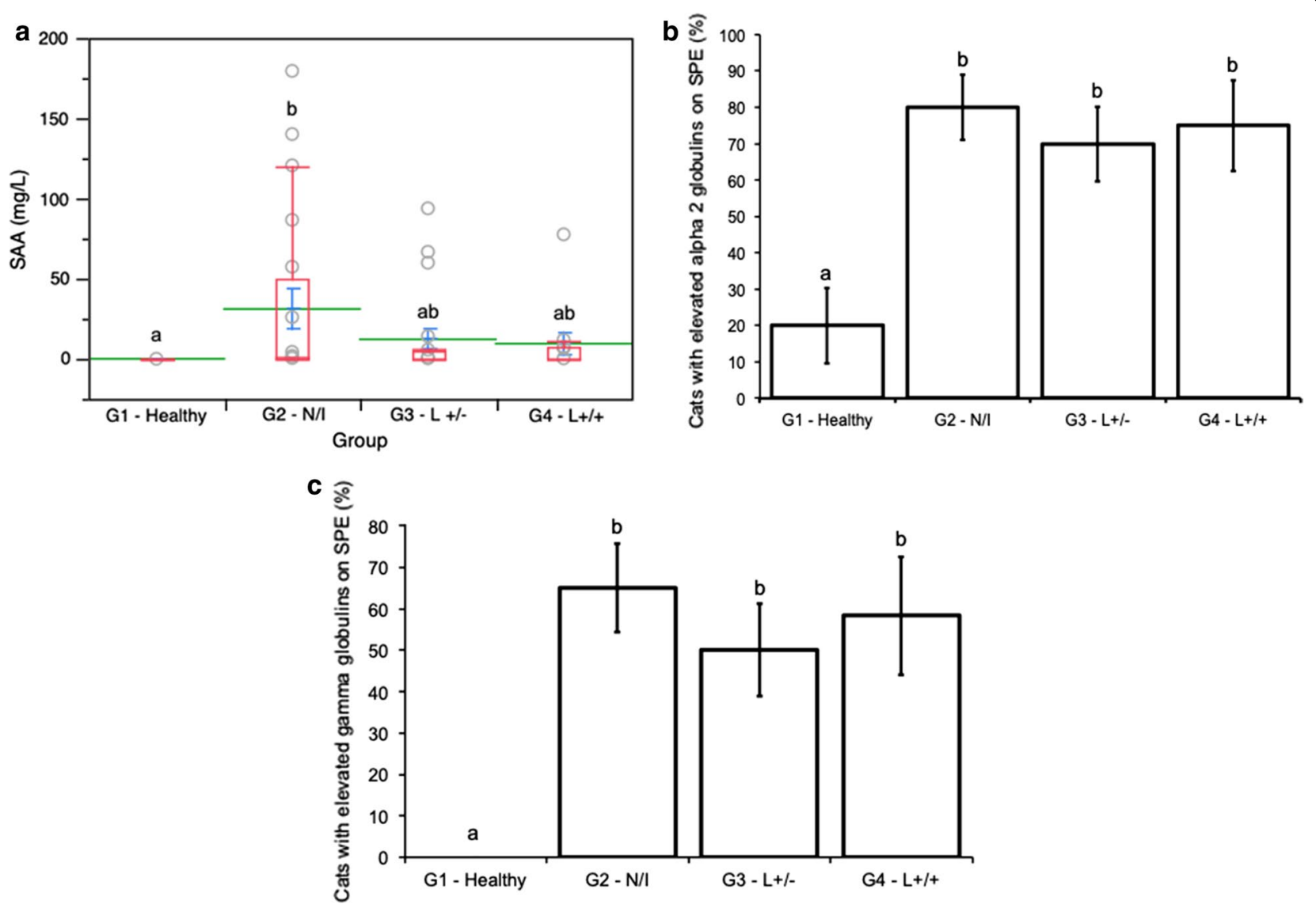

Fig. 1 Serum amyloid A (SAA) concentrations (a), and proportions of cats showing increased alpha 2 globulins (b) and increased gamma globulins (c) on serum protein electrophoresis (SPE), in healthy control cats (G1: $n=16 ; 15$ serum samples for SPE), cats affected by neoplastic or inflammatory conditions (N/I) $(G 2: n=20)$, cats seropositive and qPCR-negative for Leishmania infantum $(L+/-)(G 3: n=20)$ and cats seropositive and qPCR-positive for $L$. infantum $(L+/+)(G 4: n=12 ; 11$ serum samples for $S A A)$. a Red boxplots indicate the median (solid line) within each box and the range of dispersion (lower and upper quartiles and outliers); means and standard errors are represented by green lines and blue T-bars, respectively; the letters above boxplots indicate significant differences among groups (Dunn's test with Bonferroni correction, $P<0.05$ ). $\mathbf{b}, \mathbf{c}$ letters above columns indicate significant differences among groups (generalised linear model, binomial distribution, $P<0.05$ )

the proportion of cats with elevated alpha 2 globulins, rather than the median alpha 2 globulin values between groups, thus aiming to answer the question of whether elevation of alpha 2 globulin values above the reference range is more common among FeL-infected cats compared to non-infected cats.

The results suggest that elevated gamma globulins are a significant feature of Leishmania infection in cats, although (as reported for alpha 2 globulins) no significant differences in gamma globulin concentrations were detected between Leishmania-infected or -exposed cats and cats with other neoplastic or inflammatory conditions. Hyperglobulinaemia has been recorded in most clinical cases of FeL $[5,14,15]$. In our study, all cases of gammopathy were polyclonal, in agreement with published typical laboratory abnormalities associated with
CanL [16] and the diagnostic recommendations for FeL [29].

There was no significant difference in SAA serum concentration, or in the percentage of animals showing elevated gamma or alpha 2 globulins, between either group of animals infected by or exposed to $L$. infantum (G3 and G4) and animals affected by neoplastic or inflammatory conditions (G2). This result suggests that gamma and alpha 2 globulins are not specific markers of FeL; however, this does not preclude their role as part of a diagnostic plan and in monitoring and assessing disease prognosis. The absence of a significant difference in gamma and alpha 2 globulins between these groups of cats suggests that these markers may be an important feature of both active infection and parasite exposure. It is also possible that G3 cats had a very low parasitaemia that went undetected by qPCR [cf. 34]. 
A limitation of our study is that the 'healthy control' animals (G1) and the neoplastic and inflammatory disease group (G2) were not tested to rule out $L$. infantum infection. However, these cats were from ZVL-free areas of Switzerland (G1) and the UK (G2), respectively, and included laboratory animals bred and kept in a controlled environment as well as blood donor cats. Furthermore, G3 and G4 animals were not tested for concurrent inflammatory disease, such as feline infectious peritonitis, sepsis or gingivitis, all of which would induce an acute phase response and elevated gamma globulins.

In conclusion, the results of this study suggest that elevated alpha 2 and gamma globulins in cats may not be used to differentiate between infection and/or exposure to L. infantum and the occurrence of other inflammatory conditions.

\section{Abbreviations}

APP: Acute phase protein; CRP: C-reactive protein; ELISA: Enzyme-linked immunosorbent assay; FeL: Feline leishmaniosis; IFAT: Immunofluorescence antibody test; qPCR: Quantitative (real-time) PCR; SAA: Serum amyloid A; SPE: Serum protein electrophoresis; ZVL: Zoonotic visceral leishmaniosis.

\section{Acknowledgements}

Many thanks to Miranda Garfoot (Queen's Veterinary School Hospital, University of Cambridge) for technical help with the laboratory methods (SPE and SAA measurement) and Eva-Maria Zottler for participating in sample collections.

\section{Authors' contributions}

GS carried out SPE and SAA measurements. GS and GB analysed and interpreted the data. GS was the main contributor in writing the manuscript, with advice and guidance from CC, GB, DO and RI. JA, MS and EB provided the samples together with advice and information. GS, JA, EB and DO contributed to study design, with guidance from all other authors. All authors read and approved the final manuscript.

\section{Funding}

The study was a veterinary final year elective project funded internally by the University of Cambridge Department of Veterinary Medicine.

\section{Availability of data and materials}

The datasets used and analysed during the current study are available from the corresponding author on reasonable request.

\section{Declarations}

\section{Ethics approval and consent to participate}

All procedures described in this work comply with the ethical standards of the relevant national and institutional guides. All samples used were surplus diagnostic samples and were not specifically collected for this study. For healthy control cats from Switzerland, the objective and design of the study were approved for owned, shelter and stray cats by the owners, shelter administrator and animal welfare organisers of the neutering campaigns, respectively. Written consent was obtained from all owners of patients at the Queen's Veterinary School Hospital of the University of Cambridge, permitting surplus diagnostic samples to be used for research. All samples are archived according to the Department of Veterinary Medicine animal welfare guidelines. Cats from ZVL-endemic areas were sampled under the framework of a field study approved by the Italian Ministry of Health (authorisation no. 0006088-10/03/2015-DGSAF-COD_UO-P), and the cats' owners provided signed informed consent before sampling.
Consent for publication

Not applicable.

\section{Competing interests}

The authors declare that they have no competing interests.

\section{Author details}

${ }^{1}$ Department of Veterinary Medicine, University of Cambridge, Cambridge, UK. ${ }^{2}$ Dipartimento di Scienze Veterinarie, Università degli Studi di Messina, Messina, Italy. ${ }^{3}$ Department of Agriculture, Food and Environment, University of Pisa, Pisa, Italy. ${ }^{4}$ Institute of Parasitology, Vetsuisse Faculty, University of Zurich, Zurich, Switzerland. ${ }^{5}$ Dipartimento di Medicina Veterinaria, Università degli Studi di Bari Aldo Moro, Bari, Italy.

Received: 19 January 2021 Accepted: 31 March 2021

Published online: 21 April 2021

\section{References}

1. Maroli M, Feliciangeli MD, Bichaud L, Charrel RN, Gradoni L. Phlebotomine sandflies and the spreading of leishmaniases and other diseases of public health concern. Med Vet Entomol. 2013;27:123-47.

2. WHO (World Health Organisation). Leishmaniasis. https://www.who.int/ leishmaniasis. Accessed 23 Aug 2020.

3. Baneth G, Koutinas AF, Solano-Gallego L, Bourdeau P, Ferrer L. Canine leishmaniasis - new concepts and insights on an expanding zoonosis: part one. Trends Parasitol. 2008;24:324-30.

4. Mendoza-Roldan J, Benelli G, Panarese R, latta R, Furlanello T, Beugnet $F$, et al. Leishmania infantum and Dirofilaria immitis infections in Italy, 2009-2019: changing distribution patterns. Parasit Vectors. 2020;13:193.

5. Pennisi MG, Cardoso L, Baneth G, Bourdeau P, Koutinas A, Miró G, et al. LeishVet update and recommendations on feline leishmaniosis. Parasit Vectors. 2015:8:302.

6. Soares CS, Duarte SC, Sousa SR. What do we know about feline leishmaniasis? J Feline Med Surg. 2016;18:435-42.

7. latta R, Furlanello T, Colella V, Tarallo VD, Latrofa MS, Brianti E, et al. A nationwide survey of Leishmania infantum infection in cats and associated risk factors in Italy. PLoS Negl Trop Dis. 2019;13:e0007594.

8. latta R, Zatelli A, Laricchiuta P, Legrottaglie M, Modry D, Dantas-Torres F, et al. Leishmania infantum in tigers and sand flies from a leishmaniasisendemic area, southern Italy. Emerg Infect Dis. 2020;26:1311-4.

9. Pennisi MG, Lupo T, Malara D, Masucci M, Migliazzo A, Lombardo G. Serological and molecular prevalence of Leishmania infantum infection in cats from Southern Italy. J Feline Med Surg. 2012;14:656-7.

10. Otranto D, Napoli E, Latrofa MS, Annoscia G, Tarallo VD, Greco G, et al. Feline and canine leishmaniasis and other vector-borne diseases in the Aeolian Islands: pathogen and vector circulation in a confined environment. Vet Parasitol. 2017;236:144-51.

11. Solano-Gallego L, Rodriguez-Cortes A, Iniesta L, Quintana J, Pastor J, Espada Y, et al. Cross-sectional serosurvey of feline leishmaniasis in ecoregions around the Northwestern Mediterranean. Am J Trop Med Hyg. 2007;76:676-80.

12. Maia C, Gomes J, Cristovão J, Nunes M, Martins A, Rebelo E, et al. Feline Leishmania infection in a canine leishmaniasis endemic region, Portugal. Vet Parasitol. 2010;174:336-40.

13. Nasereddin A, Salant H, Abdeen Z. Feline leishmaniasis in Jerusalem: serological investigation. Vet Parasitol. 2008;158:364-9.

14. Fernandez-Gallego A, Bernabe LF, Dalmau A, Esteban-Saltiveri D, Font A, Leiva $M$, et al. Feline leishmaniosis: diagnosis, treatment and outcome in 16 cats. J Feline Med Surg. 2020;22:993-1007.

15. Pennisi MG, Hartmann K, Lloret A, Addie D, Belák S, Boucraut-Baralon C, et al. Leishmaniasis in cats ABCD guidelines on prevention and management. J Feline Med Surg. 2013;15:638-42.

16. Paltrinieri S, Gradoni L, Roura X, Zatelli A, Zini E. Laboratory tests for diagnosing and monitoring canine leishmaniasis. Vet Clin Pathol. 2016:45:552-78.

17. Martínez-Subiela S, Tecles F, Parra MD, Ceron JJ. Acute phase proteins: general concepts and main clinical applications in veterinary medicine. An Vet (Murcia). 2001;17:99-116. 
18. Eckersall PD, Bell R. Acute phase proteins: biomarkers of infection and inflammation in veterinary medicine. Vet J. 2010;185:23-7.

19. Martínez-Subiela S, Tecles F, Eckersall PD, Ceron JJ. Serum concentrations of acute phase proteins in dogs with leishmaniasis. Vet Rec. 2002;150:241-4.

20. Cerón JJ, Eckersall PD, Martínez-Subiela S. Acute phase proteins in dogs and cats: current knowledge and future perspectives. Vet Clin Pathol. 2005;34:85-99.

21. Martínez-Subiela S, Ceron JJ. Serum amyloid A levels in canine leishmaniasis. Vet Clin Pathol. 2002;31:205.

22. Kajikawa T, Furuta A, Onishi T, Tajima T, Sugii S. Changes in concentrations of serum amyloid A protein, alpha-1-acid glycoprotein, haptoglobin, and C-reactive protein in feline sera due to induced inflammation and surgery. Vet Immunol Immunopathol. 1999;68:91-8.

23. Sasaki K, Ma Z, Khatlani T, Okuda M, Inokuma H, Onishi T. Evaluation of feline serum amyloid A (SAA) as an inflammatory marker. J Vet Med Sci. 2003;65:545-8.

24. Tamamoto T, Ohno K, Ohmi A, Goto-Koshino Y, Tsujimoto H. Verification of measurement of the feline serum amyloid A (SAA) concentration by human SAA turbidimetric immunoassay and its clinical application. J Vet Med Sci. 2008;70:1247-52

25. Vilhena H, Tvarijonaviciute A, Cerón JJ, Vieira L, Pastor J, Silvestre-Ferreira AC. Acute phase proteins response in cats naturally infected with Hepatozoon felis and Babesia vogeli. Vet Clin Pathol. 2017;46:72-6.

26. Cavalera MA, latta R, Laricchiuta P, Passantino G, Abramo F, MendozaRoldan JA, et al. Clinical, haematological and biochemical findings in tigers infected by Leishmania infantum. BMC Vet Res. 2020;16:214

27. Taylor SS, Tappin SW, Dodkin SJ, Papasouliotis K, Casamian-Sorrosal D, Tasker S. Serum protein electrophoresis in 155 cats. J Feline Med Surg. 2010;12:643.
28. Spada E, Perego R, Vitale F, Bruno F, Castelli G, Tarantola G, et al. Feline Leishmania spp. infection in a non-endemic area of Northern Italy. Animals. 2020;10:817.

29. Urbani L, Tirolo A, Salvatore D, Tumbarello M, Segatore S, Battilani M, et al. Serological, molecular and clinicopathological findings associated with Leishmania infantum infection in cats in Northern Italy. J Feline Med Surg. 2020;22:935-43.

30. Maia C, Campino L. Biomarkers associated with Leishmania infantum exposure, infection, and disease in dogs. Front Cell Infect Microbiol. 2018;8:302.

31. Otranto D, Paradies P, De Capraris D, Stanneck D, Testini G, Grimm F, et al. Toward diagnosing Leishmania infantum infection in asymptomatic dogs in an area where leishmaniasis is endemic. Clin Vaccine Immunol. 2009;16:337-43.

32. latta R, Trerotoli P, Lucchese L, Natale A, Buonavoglia C, Nachum-Biala $Y$, et al. Validation of a new immunofluorescence antibody test for the detection of Leishmania infantum infection in cats. Parasitol Res. 2020;119:1381-6.

33. Francino O, Altet L, Sanchez-Robert E, Rodriguez A, Solano-Gallego L, Alberola J, et al. Advantages of real-time PCR assay for diagnosis and monitoring of canine leishmaniosis. Vet Parasitol. 2006;137:214-21.

34. Gradoni L, Gramiccia M. Leishmaniasis in OIE manual of standards for diagnostic tests and vaccine. 4th ed. Paris: Office International des Epizooties; 2008. p. 803-12.

\section{Publisher's Note}

Springer Nature remains neutral with regard to jurisdictional claims in published maps and institutional affiliations.
Ready to submit your research? Choose BMC and benefit from:

- fast, convenient online submission

- thorough peer review by experienced researchers in your field

- rapid publication on acceptance

- support for research data, including large and complex data types

- gold Open Access which fosters wider collaboration and increased citations

- maximum visibility for your research: over $100 \mathrm{M}$ website views per year

At $\mathrm{BMC}$, research is always in progress.

Learn more biomedcentral.com/submissions 